\title{
Influence of biobased polyol type on the properties of polyurethane hotmelt adhesives for footwear joints
}

\author{
M. P. Carbonell-Blasco ${ }^{*}$, M. A. Pérez-Limiñana, C. Ruzafa-Silvestre, F. Arán-Ais and E. Orgilés-Calpena
}

${ }^{*}$ Correspondence: pcarbonell@inescop.es INESCOP. Footwear

Technological Centre, Elda 03600, Alicante, Spain

\begin{abstract}
Polyurethanes, one of the most used polymers worldwide, are strongly dependent of non-renewable fossil resources. Thus, boosting the production of new polyurethanes based on more sustainable raw materials is crucial to move towards the footwear industry decarbonisation. The aim of this study is to synthesise and characterise reactive hotmelt polyurethanes from biomass and $\mathrm{CO}_{2}$-based polyols as bioadhesives for the footwear industry. The influence of biobased polyols on the polyurethane structure, and therefore, on their final properties was analysed by different experimental techniques such us Fourier transform infrared spectroscopy (FTIR), Differential scanning calorimetry (DSC), Thermogravimetric analysis (TGA), Melting viscosity, Softening temperature and T-peel strength test, in order to assess their viability for the upper to sole bonding process. The results obtained indicated that the incorporation of different amounts of the biobased polyols produces changes in the structure and final performance of the polyurethanes. Therefore, adhesion test carried out by the T-peel test $72 \mathrm{~h}$ after the upper -to- sole bonding of the sustainable adhesives show high final adhesion values. These sustainable raw materials provide polyurethane adhesives with additional beneficial non-toxicity and sustainable characteristics, without harming their properties during their useful life.
\end{abstract}

Keywords: Sustainability, Footwear, Adhesives, Bio-based polyurethanes, Biobased polyol, $\mathrm{CO}_{2}$-based polyol

\section{Introduction}

The sustainable use of resources in the production, use and disposal of a product is one of the current challenges that the European industry faces, which demands innovative developments in materials and joining technologies implementing the circular economy model $[1,2]$. Due to the continuous development of raw materials, adhesives and adhesive bonding products, adhesive bonded technologies have gained a high level of acceptance in recent decades. In view of the steadily increasing regulatory requirements, a wide range of innovative solutions are already being successfully implemented through more environmentally friendly adhesive developments [3].

(c) The Author(s), 2021. Open Access This article is licensed under a Creative Commons Attribution 4.0 International License, which permits use, sharing, adaptation, distribution and reproduction in any medium or format, as long as you give appropriate credit to the original author(s) and the source, provide a link to the Creative Commons licence, and indicate if changes were made. The images or other third party material in this article are included in the article's Creative Commons licence, unless indicated otherwise in a credit line to the material. If material is not included in the article's Creative Commons licence and your intended use is not permitted by statutory regulation or exceeds the permitted use, you will need to obtain permission directly from the copyright holder. To view a copy of this licence, visit http:// creativecommons.org/licenses/by/4.0/. 
In several industrial sectors, the use of polyurethanes is key to the development of innovative and sustainable products. At present, the raw materials used to produce these polyurethanes come mainly from non-renewable fossil resources, which means that they need to be replaced by other low-carbon materials of renewable origin. Therefore, in the polymer industry, and specifically, in the polyurethanes sector, there is a occurrent towards sustainable products that minimise the use of petroleum resources, without worsening their performance [4].

There are various alternatives for obtaining polyurethane from renewable raw materials such as vegetable oils (soya, sunflower, etc.). In recent years, they are one of the main alternatives to end the use of petroleum-derived materials in the production of polyols, these being the basic raw material for the development of polyurethane [5]. The recent alternatives use as a reagent for the synthesis of polymers represents numerous advantages, for instance their biodegradability, low toxicity, sustainability, industrial viability, cost competitiveness and design of final polymer properties. Over the last few years, many studies have been carried out which have allowed the substitution of fuel oil as a raw material base, such as, soybean, sunflower, rapeseed, linseed and castor oils are the most commonly used in polymer synthesis through chemical modification [6-8].

The major components of vegetable oils are triglycerides, which are esters of glycerol with three long-chain fatty acids [9]. Fatty acids can be obtained from these vegetable oils by hydrolysis and subsequently transformed into polyols through different production routes (epoxidation, ozonolysis...) [10-12].

Another alternative to produce polyurethane is the use of carbon dioxide $\left(\mathrm{CO}_{2}\right)$ as a reagent base for polymer synthesis. $\mathrm{CO}_{2}$ is one of the greenhouse gases that contributes more than $60 \%$ to global warming due to its large number of emissions into the atmosphere, which are uncontrolled emissions that could be a source of raw materials [13, 14].

Although it is true that the uncontrolled increase of this gas poses a threat to our planet, $\mathrm{CO}_{2}$ is part of our life, for example, through the breathing process of living beings. At industrial scale, it is also used as an additive in food preservation and in the carbonation of beverages such as sparkling water, soft drinks, beer, etc. $[15,16]$.

This greenhouse gas is an interesting alternative to oil, as $\mathrm{CO}_{2}$ is a useful, versatile, non-flammable product and is abundant in the atmosphere. In particular, carbon dioxide can be used for the production of polyols, as in the case of vegetable oils. This is a significant innovation, as this greenhouse gas leads to a future sustainable raw material for the chemical industry $[17,18]$.

Polyurethanes, whose history is relatively short at just over 80 years, constitute the most versatile family of polymers currently in existence, due to their properties being suitable for a wide range of applications, such as foams, elastomers, thermoplastics, thermosets, adhesives, coatings, sealants, fibres, paints, etc. [19, 20].

Specifically, in the footwear sector, polyurethanes (PU) are one of the most used materials, in insoles, coatings, elastomers, adhesives, etc., thanks to their great versatility [21]. Indeed, Thermoplastic polyurethanes (TPUs) are a relevant class of thermoplastic elastomers with a wide variety of compositions and properties. Similarly, Polyurethane adhesives are of great importance in the footwear sector, fulfilling technical requirements across the wide range of materials used in footwear manufacturing [22]. 
Polyurethane adhesives are highly versatile and can be designed with tailor-made and improved properties, including sustainable ones, through the selection of their reagents [23, 24]. The substitution of reagents from fossil resources with those from biological sources or $\mathrm{CO}_{2}$ as a reagent base for polymer synthesis provides them with additional beneficial nontoxic and ecological characteristics, without detriment to their performance for application in the footwear industry [25-30].

In this work, INESCOP (Footwear Technology center) focuses on the synthesis and characterisation of polyurethane reactive hotmelt bioadhesives based on polyols from renewable sources or from $\mathrm{CO}_{2}$ captured in industrial environments, allowing the reduction or removing fossil-based raw materials, and opting for eco-friendly ones. These sustainable raw materials provide polyurethane adhesives with additional beneficial non-toxicity and sustainable characteristics, without harming their properties during their useful life.

\section{Experimental}

Synthesis of polyurethanes for reactive hotmelt adhesive (HMPUR)

Reactive polyurethane hotmelt adhesives were synthesised from several macroglycol mixtures of polyadipate of 1,4-butanediol (Hoopol F-580, Synthesia Technology, Barcelona, Spain) [31] with an average molecular weight ( $\mathrm{Mw})$ of $2826 \mathrm{~g} \mathrm{~mol}^{-1}$ polypropylene glycol (PPG, Quimidroga SA. Barcelona, Spain, $\mathrm{Mw}=425 \mathrm{~g} \mathrm{~mol}^{-1}$ ) and a biobased polyol (BIO HOOPOL, Synthesia Technology, Spain) [32]. According to its technical datasheet, this macroglycol is based on a saturated crystalline polyester polyol synthesised using $100 \%$ renewable monomers from biomass. The $\mathrm{CO}_{2}$-based polyol (Cardyon, Covestro, Leverkusen, Deutschland) [33] has an average molecular weight of $\mathrm{Mw}=2000 \mathrm{~g} \mathrm{~mol}^{-1}$ and is based on polyether carbonate diol synthesised using $15 \% \mathrm{CO}_{2}$. Besides, mdi, 4-4'methylene diphenyl diisocyanate (Sigma-Aldrich, Barcelona, Spain) was used as a diisocyanate as it is solid, and it is the best performing to produce polyurethane adhesives with the appropriate characteristics for their final application at present.

The prepolymer mixing method was used for the synthesis of reactive polyurethane hotmelt adhesives, using an optimal $\mathrm{NCO} / \mathrm{OH}$ index of 1.5 . And they were synthesised under a nitrogen atmosphere at $90{ }^{\circ} \mathrm{C}$ in a glass vessel placed in an oil bath and equipped with a mechanical stirrer, according to previous research carried out by the authors $[15,18,34]$.

The refenced reactive polyurethane hotmelt adhesive (PUREF) was obtained by equal mixing of polyadipate of 1,4-butanediol and propylene glycol. For the incorporation of biobased polyol $(\mathrm{BH})$ or $\mathrm{CO}_{2}$-based polyol (C), the propylene glycol (PPG) was partially replaced in the formula according to Table 1.

The percentage of free NCO was calculate applying the n-dibutylamine titration method. Once the desired index is reached, the reaction was stopped [35]. Then, the HMPUR adhesive obtained was stored in hermetic disposable cartridges to be applied later by a manual hot melt applicator.

\section{Experimental techniques}

\section{Softening temperature}

The determination of the softening temperature of the HMPUR was assessed according to EN1238 [36]. The softening temperature indicates the temperature above which the viscous properties of the adhesive become dominant. The standard test defines the 
Table 1 Reactive polyurethane hotmelt adhesives nomenclature obtained by partial substitution of polypropylene glycol (PPG) by biobased polyol (BH) or $\mathrm{CO}_{2}$-based polyol (C)

\begin{tabular}{lcll}
\hline $\begin{array}{l}\text { HMPUR } \\
\text { nomenclature }\end{array}$ & $\begin{array}{l}\text { Biobased or } \mathrm{CO}_{2} \text { based } \\
\text { polyol (wt\%) }\end{array}$ & $\begin{array}{l}\text { Polypropylene } \\
\text { glycol (wt\%) }\end{array}$ & Diisocyanate \\
\hline PUREF & 0 & 100 & $4-4^{\prime}$ methylene diphenyl diisocyanate \\
PUR 25BH & 25 & 75 & \\
PUR 50BH & 50 & 50 & \\
PUR 75BH & 75 & 25 & \\
PUR 25 C & 25 & 75 & \\
PUR 50 C & 50 & 50 & \\
PUR 75 C & 75 & 25 & \\
\hline
\end{tabular}

softening temperature as the temperature at which a steel ball passes through a ring filled with adhesive while immersed in a water, glycerol or mineral oil bath (depending on the softening temperature).

\section{Melting viscosity}

The apparent viscosity of the reactive polyurethane hotmelt adhesive was evaluated using a Brookfield Thermosel viscometer equipped with an SC4-27 spindle according to the test procedure described in the ASTM D3236-15 standard [37]. This consists of thermostatised camera which melts the adhesive, allowing the viscosity to be measured at a controlled temperature. This value determines the ease or difficulty of the application of the adhesive to the substrate, the working temperature, the open time, etc.

\section{Fourier Transform Infrared Spectroscopy (FTIR)}

The chemical properties of the HMPUR adhesive were determined using a Varian 660IR infrared spectrophotometer (Varian Australia PTY LTD; Mulgrave, Australia). Attenuated total reflection (ATR) technology was used to perform 16 scans at a resolution of $4 \mathrm{~cm}^{-1}$.

\section{Thermogravimetric analysis (TGA)}

The thermal stability of HMPUR was performed using a TGA 2 STARe System thermal balance equipped with STARe software (Mettler-Toledo, Switzerland). Approximately 7 to $10 \mathrm{mg}$ of adhesive sample is placed in an alumina crucible. The sample was heated from 30 to $600{ }^{\circ} \mathrm{C}$ at $10{ }^{\circ} \mathrm{C} \mathrm{min}{ }^{-1}$ in an inert nitrogen atmosphere (flow rate $=30 \mathrm{~mL}$ $\left.\min ^{-1}\right)$.

\section{Differential Scanning Calorimetry (DSC)}

The thermal properties of polyurethane adhesives were studied using a DSC3 + STARe Systems calorimeter (Mettler-Toledo AG, Schwerzenbach, Switzerland). Samples of approximately 9-12 $\mathrm{mg}$ in an aluminium pan was employed. The experiments were conducted in an inert nitrogen atmosphere (flow rate $=30 \mathrm{~mL} \mathrm{~min}^{-1}$ ) at a heating or cooling rate of $10{ }^{\circ} \mathrm{C} \mathrm{min}{ }^{-1}$. Two consecutive runs were completed: (i) heating from -15 to $110{ }^{\circ} \mathrm{C}$, then isothermally heating at $110{ }^{\circ} \mathrm{C}$ for $3 \mathrm{~min}$ to eliminate the thermal history of the sample; (ii) the second heating from $-65^{\circ} \mathrm{C}$ to $100{ }^{\circ} \mathrm{C}$, followed by isothermal 
cooling at $25{ }^{\circ} \mathrm{C}$ for $45 \mathrm{~min}$. The optimal conditions for DSC experiments were previously optimised by the author in a previous work [38].

\section{T-peel strength test}

Adhesion properties were evaluated according to the procedure described in the standard EN 1392:2007 [39]. Standard materials were used as a soling and upper material as adherent: vulcanised rubber SBR-2 and a chrome-tanned split leather, respectively. The split leather was provided by the Spanish company "Palomares Piel, S.L" (Elda, Spain). In this way, the bondability of HMPURs was evaluated in split leather/SBR rubber joints.

Before joint formation, each adherent was duly treated. Split leather test samples were roughened at $2800 \mathrm{rpm}$ with a P100 aluminium oxide abrasive cloth (Due Emme Abrasivi, Pavia, Italy) using a roughing machine (Superlema S.A., Zaragoza, Spain). The SBR-2 rubber was roughened and halogenated with $2 \mathrm{wt} \%$ trichloroisocyanuric acid solutions in ethyl acetate. Both are typical treatment in the footwear industry today. The following procedure was used to prepare adhesive bonded joints of $150 \times 30 \mathrm{~mm}$ (SBR rubber/HMPUR/leather).

Joint formation was carried out after $30 \mathrm{~min}$ since the adhesive application. To enhance contact between both adhesive films, the substrates were activated by infrared radiation at $80{ }^{\circ} \mathrm{C}$ in a CAN $02 / 01$ temperature-controlled heater provided by $\mathrm{AC} \& \mathrm{~N}$ (Elda, Spain). The strips were immediately placed in contact with each other and a pressure of 1.8 bar was applied for $10 \mathrm{~s}$ to achieve a suitable joint. Then, adhesive joints were stored at $23{ }^{\circ} \mathrm{C}$ and $50 \%$ relative humidity for $72 \mathrm{~h}$. Finally, T-peel strength measurement was performed in an Instron 1011 universal testing machine (Instron Ltd, Buckinghamshire, UK) at a crosshead speed of $100 \mathrm{~mm} / \mathrm{min}$. The bond strength values were then calculated as a function of the piece width, strength value and scale obtained with the testing machine, thus obtained an average and typical deviation of the five values for each sample.

\section{Results and discussion}

The chemical composition of the synthesised HMPUR adhesives contains different percentage of biobased polyester polyol and $\mathrm{CO}_{2}$-based polyol, which are analysed by FTIR are show in Figs. 1 and 2.

FTIR spectra show the characteristic bands of a polyurethane prepolymer adhesives and the band corresponding to free reactive isocyanate groups $(-\mathrm{N}=\mathrm{C}=\mathrm{O})$ [40]. The reactive polyurethane adhesives obtained require an excess of isocyanate to react with moisture and subsequent polymerisation or chemical curing to occur. In addition, it is worth noting some of the following bands that appear on all HMPUR adhesives: the $\mathrm{N}-\mathrm{H}$ stretching band at $3324 \mathrm{~cm}^{-1}$, the $\mathrm{C}-\mathrm{H}$ stretching band at $2840-3000 \mathrm{~cm}^{-1}$, st $\mathrm{C}=\mathrm{O}$ of ester and urethane groups at $1729 \mathrm{~cm}^{-1}$, stretching $\mathrm{C}=\mathrm{C}$ band of aromatic groups at $1600 \mathrm{~cm}^{-1}$, the stretching $\mathrm{CN}$ and $\delta \mathrm{NH}$ band at $1527 \mathrm{~cm}^{-1}$, and the reactive isocyanate group at $2270 \mathrm{~cm}^{-1}$.

Specifically, when the biobased polyol was used, the intensity of the $\mathrm{C}=\mathrm{C}$ band (characteristic aromatic group) at $1600 \mathrm{~cm}^{-1}$ is also reduced, which indicates that the isocyanate content in the polyurethane formulation is lower, thus confirming the lower urethane content in the polyurethane using biobased polyester polyol. In the 

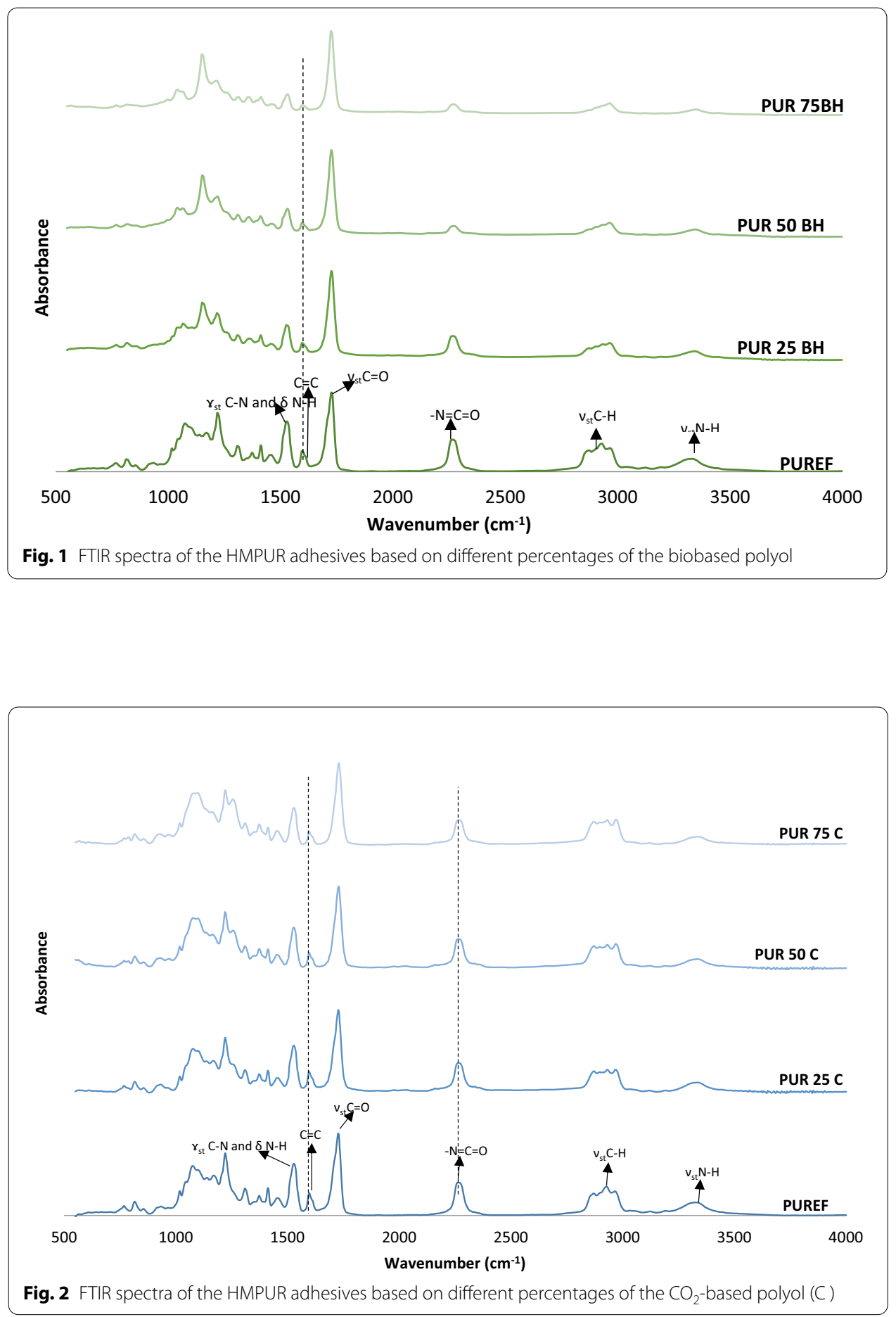

case of $\mathrm{CO}_{2}$-based polyols this reduction occurs more slightly in the HMPUR adhesives. The FTIR spectra also show the characteristic C-O stretching bands of macromolecular diols at 1220,1162, 1075 and $965 \mathrm{~cm}^{-1}$. The relative intensity of the NCO band decreases as the content of biobased polyol increases, which is in line with the theoretical values in both news polyols. 
The HMPUR adhesives obtained with biobased and $\mathrm{CO}_{2}$ - based polyols were evaluated by DSC experiments to understand their thermal behaviour.

The DSC curves of the HMPUR adhesives corresponding to the second heating run, after thermal annealing are shown in Figs. 3 and 4. DSC thermograms of the reactive hotmelt adhesives show the glass transition temperature $(\mathrm{Tg})$ at low temperature, decreasing slowly from -14.2 to $-23{ }^{\circ} \mathrm{C}$ when the percentage of biobased polyol and $\mathrm{CO}_{2}$-based polyol increase respectively. This change may be due to lower mobility due to the increased degree of phase separation in the polyurethane [41].

The conventional urethane prepolymer (PUREF) did not show the crystallisation and melting process of the soft segments. In the case of the HMPUR adhesive with 50 and $75 \%$ of the biobased polyol show the melting process of the soft segments, due to the crystalline nature of the biobased polyol, therefore the incorporation of biobased polyol changes the structure of HMPUR adhesives (Table 2).

By contrast, when used as a $\mathrm{CO}_{2}$-based polyol, the HMPUR adhesives based on this polyol only show glass transition temperature $(\mathrm{Tg})$ according to the similarity of the $\mathrm{CO}_{2}$ based polyol with the conventional polyol.

The thermal stability of the synthesised bio-based or $\mathrm{CO}_{2}$-based HMPUR adhesives was studied by thermogravimetric analysis (TGA). Figures 5 and 6 show the thermograms of the HMPUR adhesives obtained by the substitution of different percentages of the polypropylene glycol with a biobased polyol and $\mathrm{CO}_{2}$-based polyol, respectively. The thermograms show, the decomposition of all HMPUR adhesives occurs in two stages, occurring around 300 and $400{ }^{\circ} \mathrm{C}$, respectively, calculated at the maximum of the first derivate in DTA thermograms (Figs. 5 and 6).

The partial substitution of the propylene glycol by the biobased polyol produces an increase in thermal stability evidence by an increase in the decomposition temperature,

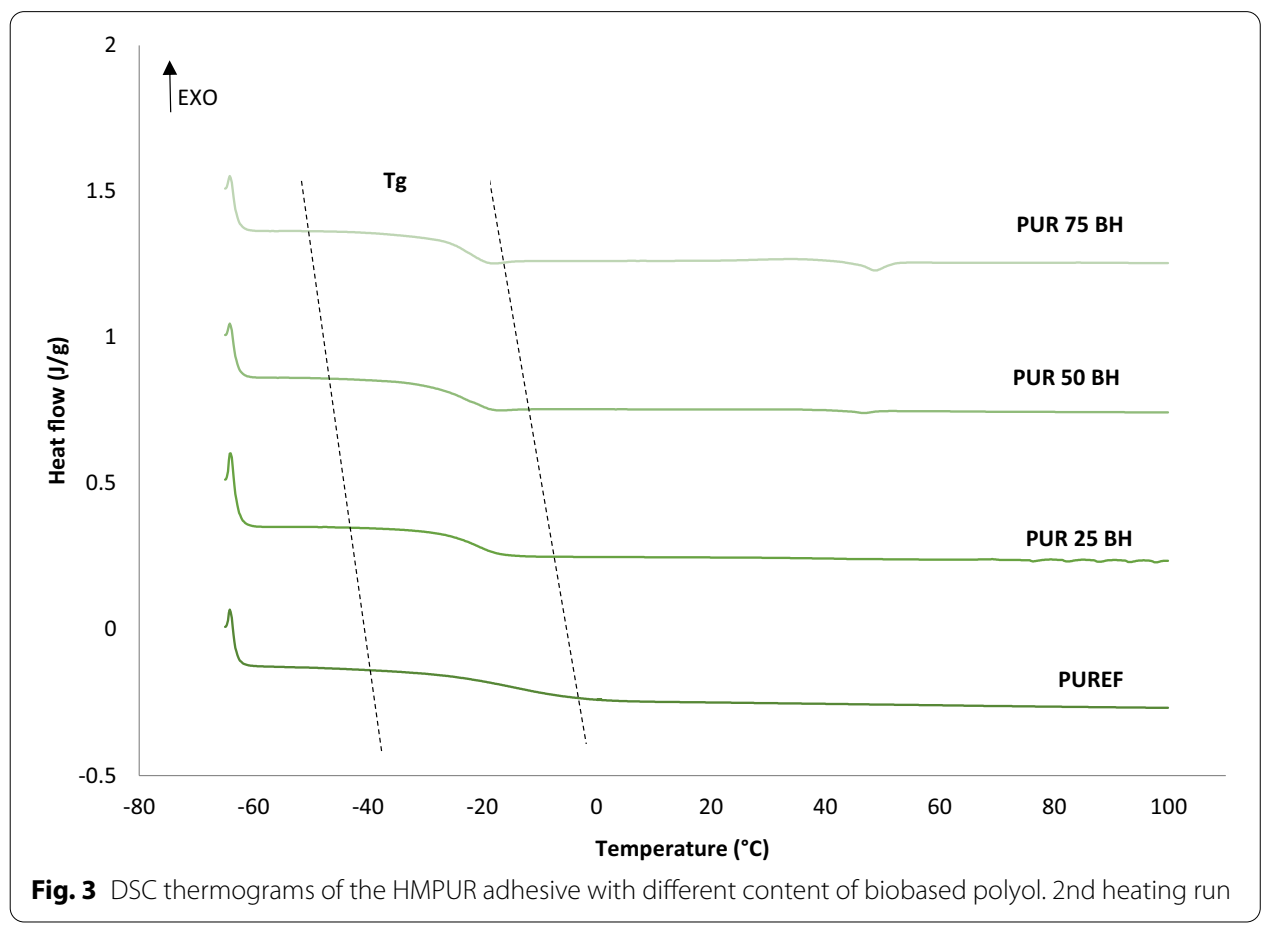




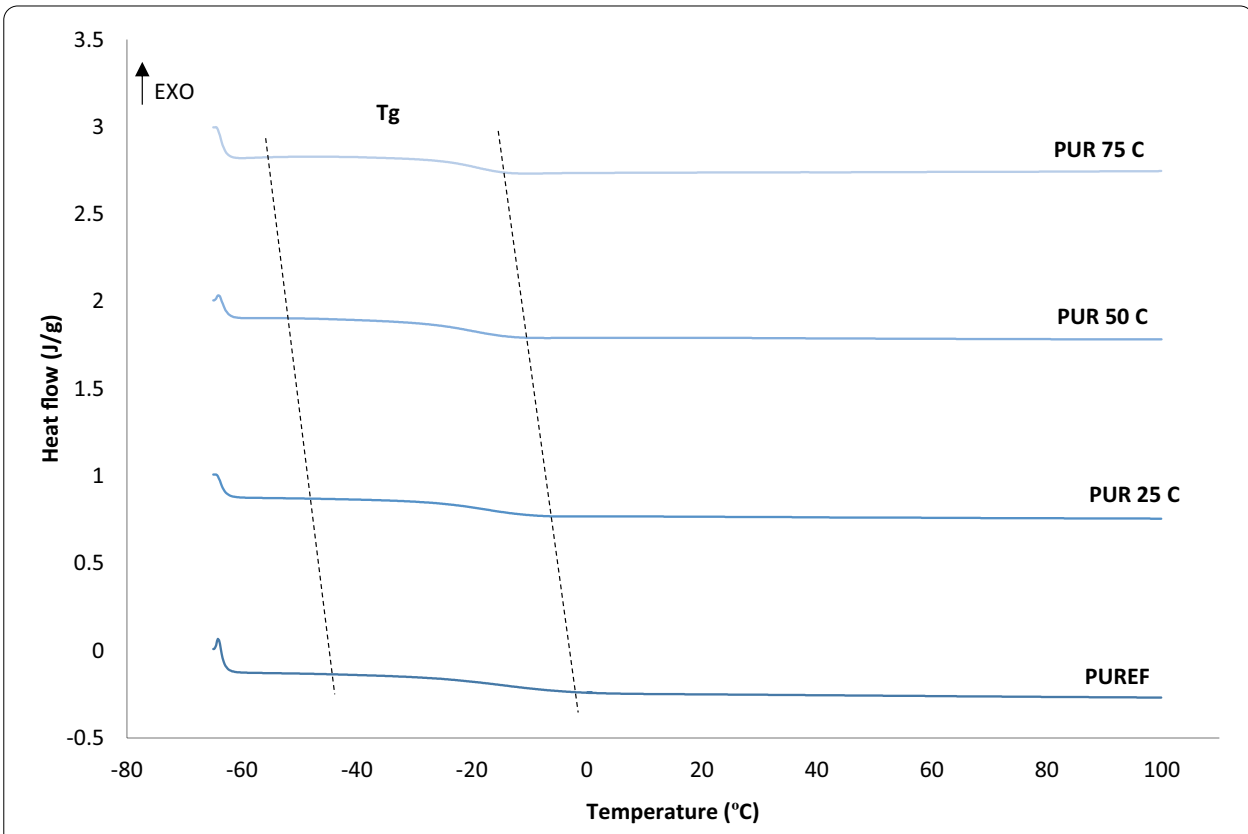

Fig. 4 DSC thermograms of the HMPUR adhesive with different content of $\mathrm{CO}_{2}$-based polyol respectively. 2nd heating run

Table 2 DSC results of the HMPUR adhesives calculated from 2nd heating run

\begin{tabular}{lccc}
\hline HMPUR adhesives & $T_{g}\left({ }^{\circ} \mathrm{C}\right)$ & $T_{m}\left({ }^{\circ} \mathbf{C}\right)$ & $\Delta H_{m}(\mathbf{J} / \mathbf{g})$ \\
\hline PUREF & -14.2 & - & - \\
PUR 25BH & -20.9 & - & - \\
PUR 50BH & -23.0 & 46.8 & -0.3 \\
PUR 75BH & -23.0 & 48.7 & -1.1 \\
PUR 25 C & -17.2 & - & - \\
PUR 50 C & -21.2 & - & - \\
PUR 75 C & -18.9 & - & \\
\hline
\end{tabular}
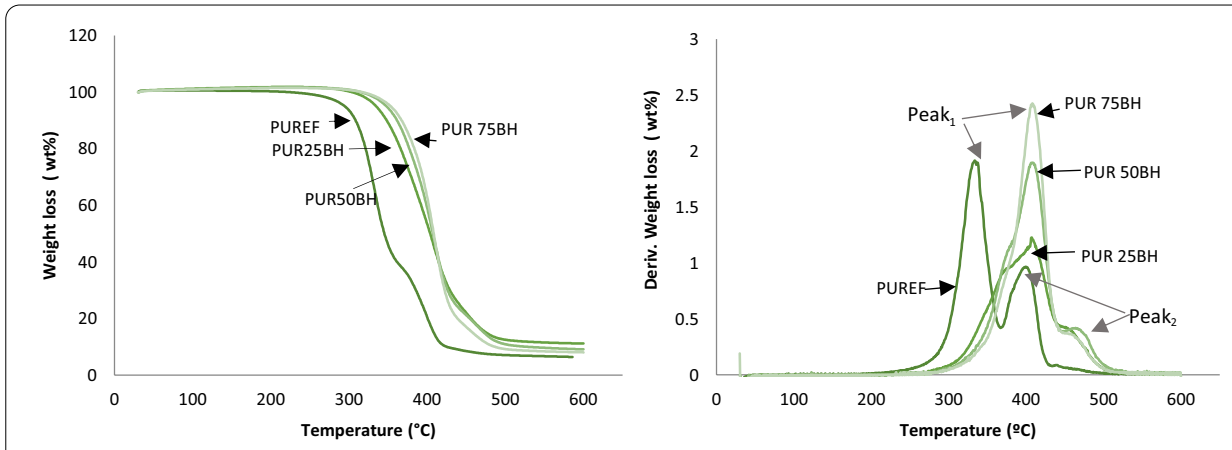

Fig. 5 TG and DTA curves of the HMPUR adhesives with different content of biobased polyol

this starts at a higher temperature than the conventional HMPUR adhesive 25, 42, produced in the first decomposition process (Fig. 5). Being more pronounced the higher the 

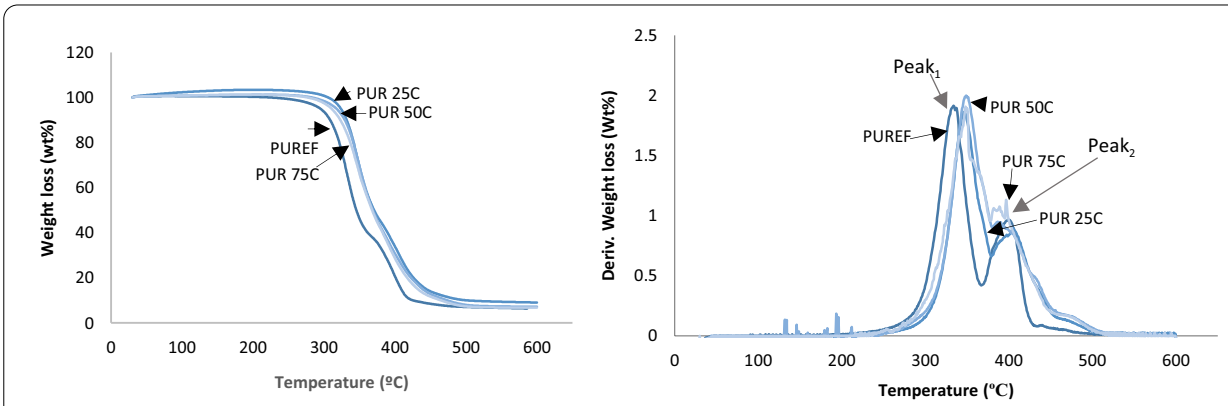

Fig. 6 TG and DTA curves of the HMPUR adhesives with different content of $\mathrm{CO}_{2}$-based polyol

amount of the biobased polyol in the HMPUR adhesives. When the $\mathrm{CO}_{2}$-based polyol is incorporated the increase in thermal stability is less marked than when the bio-based polyol is used, this is due to the different nature of the $\mathrm{CO}_{2}$-based polyol (Fig. 6, Table 3).

The melting viscosity and the soft temperature of the HMPUR synthesised are included in Table 4.

The viscosity of the HMPUR adhesives is increased by the incorporation of the of biobased polyol or the $\mathrm{CO}_{2}$-based polyol, the more propylene glycol replaced by biobased or $\mathrm{CO}_{2}$-based polyols, the higher the viscosity of the HMPUR adhesives. These changes could be attributed to an increase of the molecular weight of the polyurethane. The final application of these adhesives is not affected by the increase in viscosity, so all adhesives flow properly.

Moreover, the biobased HMPUR adhesives have a softening point similar to the conventional HMPUR adhesive around $60^{\circ} \mathrm{C}$. In the case of the biobased HMPUR adhesives present a content of $75 \%$ biobased polyol or $\mathrm{CO}_{2}$-based polyol have the same softening point as conventional HMPUR adhesive.

The adhesion properties of HMPUR adhesives with different amounts of biobased and $\mathrm{CO}_{2}$ polyols was studied by T-peel testing in leather/rubber joints, as described in Sect. 2. Figures 7 and 8 show T-peel strength after $72 \mathrm{~h}$ of joint formation as a function of the different amounts of biobased and $\mathrm{CO}_{2}$ polyols in the HMPUR adhesives, respectively.

There is a decrease in the adhesion values of the adhesives with a partial substitution of the propylene glycol polyol by biobased and $\mathrm{CO}_{2}$-based polyols adhesive failure of SBR2 rubber regards to the reference adhesive (PUREF). In addition, there is a shift in the failures since the reference adhesive has a rubber cohesive failure and all biobased and $\mathrm{CO}_{2}$-based HMPUR adhesives have adhesive failure of SBR2 rubber. All biobased HMPUR adhesives meet the minimum quality requirements demanded for footwear applications according to standard test [43].

\section{Conclusions}

The biobased and $\mathrm{CO}_{2}$-based reactive hotmelt polyurethane adhesives obtained are a new and sustainable solution that can reduce the use of fossil resources without detriment to their performance for footwear applications. 


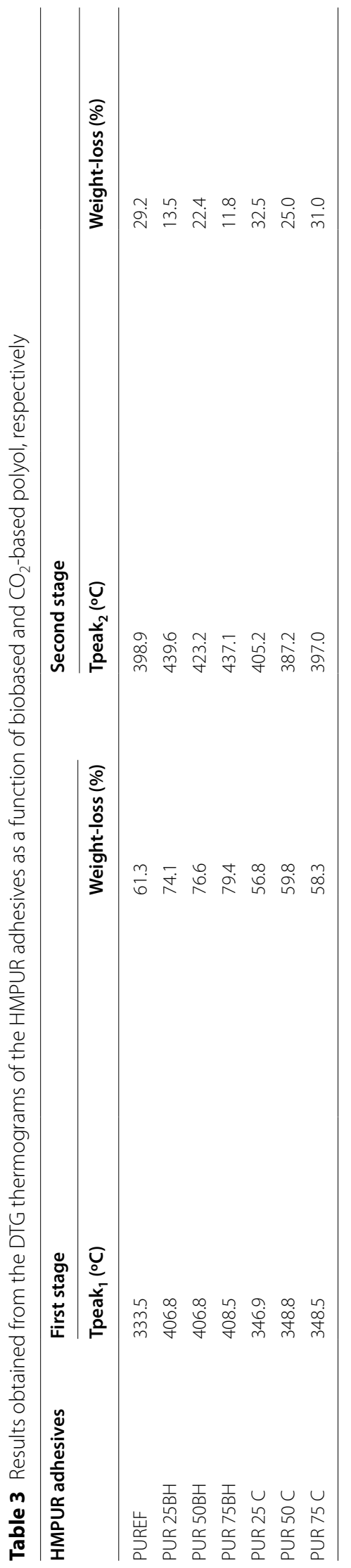


Table 4 Melting viscosity and softening point of the bio and $\mathrm{CO}_{2}$ based HMPUR adhesives

\begin{tabular}{lcc}
\hline HMPUR adhesives & Viscosity (mPa s) & $\begin{array}{l}\text { Softening } \\
\left.\text { point ( }{ }^{\circ} \mathbf{C}\right)\end{array}$ \\
\hline PUREF & 10,000 & 58 \\
PUR 25BH & 13,000 & 56 \\
PUR 50BH & 27,000 & 56 \\
PUR 75BH & 32,500 & 58 \\
PUR 25 C & 18,000 & 51 \\
PUR 50 C & 22,000 & 51 \\
PUR 75 C & 20,500 & 58 \\
\hline
\end{tabular}

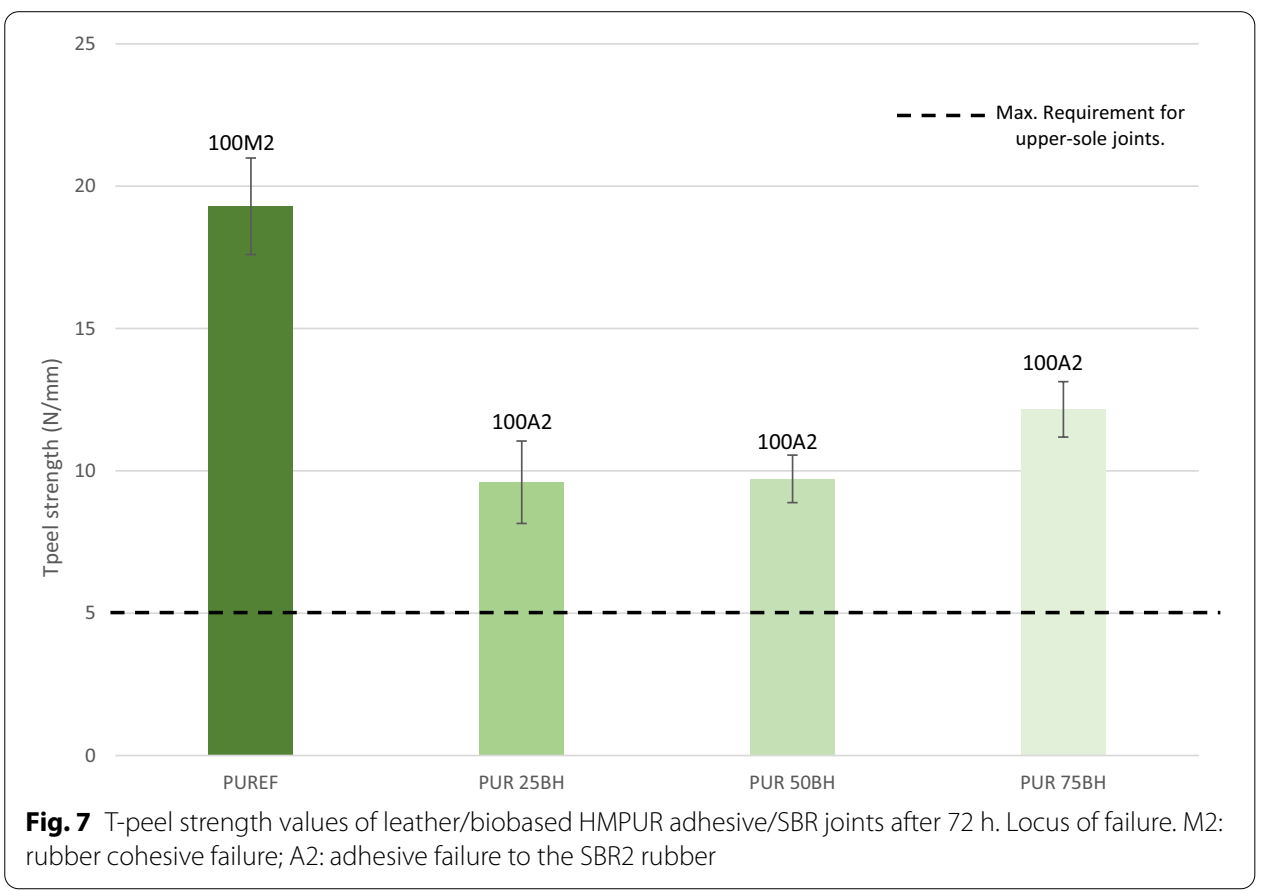

The characterisation of the HMPUR adhesives obtained shows that the incorporation of different amounts of the considered polyols produces changes in the structure and final performance of the polyurethanes. The results show that the polyurethane adhesives with different thermal stability, softening point, viscosity, molecular weight have been obtained. In addition, adhesion test carried out by the T-peel test $72 \mathrm{~h}$ after the upper-to-sole bonding of the sustainable adhesives show high final adhesion values. Thus, the new biobased and $\mathrm{CO}_{2}$-based adhesives meet the highest quality requirements in the footwear industry for upper-to-sole joints. Hence, the development of more sustainable adhesives from partial substitution of oil-based polyols by biobased or $\mathrm{CO}_{2}$-based polyols with a similar performance to the conventional adhesives is now a reality.

In conclusion, this development allows biobased reactive hotmelt polyurethane adhesives to contribute to the climate neutrality of the products where they are applied, particularly in the upper-to-sole joints in the footwear. They also contribute to the sustainable development of European footwear industry. Thereby contributing to the 


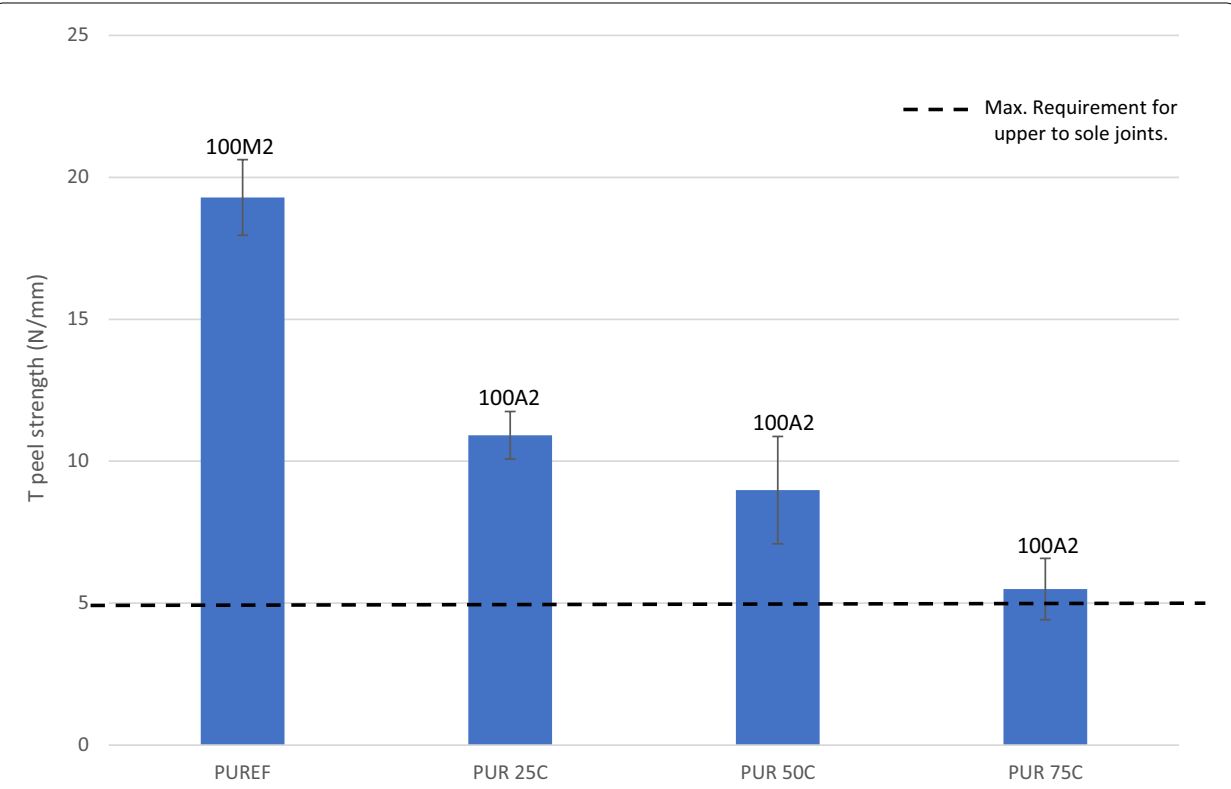

Fig. 8 T-peel strength values of leather/CO2-based HMPUR adhesive/SBR joints after 72h. Locus of failure. M2: rubber cohesive failure; A2: adhesive failure to the SBR2 rubber.

achievement of sustainable development goals (SDGs), in particular SDG 12 and 13, responsible consumption and production, and climate action. And finally with the SDG 17, because without technological cooperation all the other objectives cannot be archieved.

\section{Acknowledgements}

The author(s) disclosed receipt of following financial support for the research, authorship, and/or publication of this article: This work was founded by the Valencian Institute for Business Competitiveness (IVACE) of Generalitat Valenciana, and the European Regional Development Fund (ERDF); through the R\&D Programme for Technology Institutes 2014-2020. ECOGLUE II.

Author's contributions

MPC, MAP performed the experiments; MPC analysed the data with the support of MAP; MPC and FA wrote the paper and all authors reviewed and revised the manuscript to its final form. EO and FA supervised the entire study. All authors have read and agreed to the published version of the approved the final manuscript. All authors read and approvedthe final manuscript.

\section{Funding}

This research was founded by VALENCIAN INSTITUTE FOR BUSINESS COMPETITIVENESS (IVACE) OF GENERALITAT VALENCIANA and THE EUROPEAN REGIONAL DEVELOPMENT FUND (ERDF), Grant Number IMDEEA/2019/37, ECOGLUE.

Availability of data and materials

The data presented in this study are available upon request from corresponding author.

\section{Declarations}

Ethics approval and consent to participate

Not applicable in this section.

\section{Consent for publication}

Not applicable in this section.

\section{Competing interests}

The authors declare no conflict of interest.

Received: 15 September 2021 Accepted: 29 October 2021

Published online: 19 November 2021 


\section{References}

1. Moktadir A, Rahman T, Chiappetta Jabbour CJ, Mithun Ali S, Kabir G (2018) Prioritization of drivers of corporate social responsibility in the footwear industry in an emerging economy: a fuzzy AHP approach. J Clean Prod 201:369-381

2. Arán Aís F, Ruzafa Silvestre C, Carbonell Blasco MP, Pérez Limiñana MA, Orgilés Calpena E (2020) Sustainable adhesives and adhesion processes for the footwear industry. Proceedings of the intution of mechanical engineering science. J Mech Eng Sci 12:8

3. Polese F, Vincenza Ciasullo M, Troisi O, Maione G (2019) Sustainability in footwear industry: a big data analysis. Sinergie italian journal of management. Transformative business strategies and new patterns for value creation 37:149-170

4. Gadhavem RV, Mahanwar PA, Gadekar PT (2017) Biorenewable sources for synthesis of eco-friendly polyurethane adhesives- review. Open J Polym Chem 7:57-75

5. Mokhtari C, Malek F, Halila S, Belgacem MN (2021) Khiari R New biobased polyurethane materials from modified vegetable oil. J Renew Mater. 9(7):1213-1223

6. Zhang C, Madbouly SA, Kessler MR (2015) Biobased polyurethanes prepared from different vegetable oils. ACS Appl Mater Interfaces 7(2):1226-1233

7. Datta J, Glowinska E (2014) Chemical modifications of natural oils and examples of their usage for polyurethane synthesis. J Elastomers Plast 46:33-42

8. Liu X, Su H, Pang Y, Yang D, Jiang Y, Mao A (2019) Synthesis and properties of bio-based adhesives derived fro, plant oil residues. Am J Modern Energy 5:94-99

9. Patil CK, Rajput SD, Maratge RJ, Kulkarni RD, Phadnis H, Sohn D, Mahulikar PP, Gite WV (2017) Synthesis of bio-based polyurethane coating from vegetable oil and dicarboxylic acids. Progress in Organic Coating 106:87-95

10. MA Ser. Polyurethanes from vegetable oils and applications: a review. J Polym Res. 2018; 25:184

11. Petrovic (2008) Polyurethanes from vegetable oils. Polymer Reviews 48:109-155

12. Petrovic ZS, Xu Y, Milíc J, Glenn G, Klamczynski A (2010) Biodegradation of thermoplastic polyuerthanes from vegetables oils. J Polym Environ 18:94-97

13. Waddington $\mathrm{S}$ (2014) $\mathrm{CO}_{2}$ based polyols give enhanced properties in reactive hot-melts. In: Proc. FEICA international conference, Berlin, Germany. 17-19 September 2014

14. Xu Y, Lin L, Xiao M, Wang S, Smith AT, Sun L, Meng Y (2018) Synthesis and properties of CO2- based plastics: Environmentally-friendly, energy-saving and biomedical polymeric materials. Prog Polym Sci 80:163-182

15. Orgilés Calpena E, Arán Aís F, Torró Palau AM, Montiel Parreño E, Orgilés Barceló C (2016) Synthesis of polyuethanes from CO2-based polyols: a challenge for sustainable adhesives. Int J Adhes Adhes 67:63-68

16. Liu S, Wang X (2017) Polymers from carbon dioxide: Polycarbonates, polyurethanes. Curr Opin Green Sustain Chem. 3:61-66

17. Verlag G (2013) $\mathrm{CO}_{2}$ as a polyol intermediate: the dream becomes a reality. Pu Magazine

18. Cherian A. Novel $\mathrm{CO}_{2}$-based polycarbonate polyols for high performance polyurethane hot-melt adhesives. In: Proc. polyurethanes technical conference. Dallas, TX: s.n., 17-19 de September de 2014

19. Orgilés-Calpena E, Arán-Aís F, Torró-Palau AM, Martínez-Sánchez MA (2019) Adhesives in the footwear industry: a critical review. Rev Adhes Adhes. 7(1):69-91

20. Dieterich D, Girgat E, Hahn W (1993) Chemical and physical-chemical principles of polyurethane chemistry. Oërtel G (ed). Polyurethane Handbook. Munich Alemania: 1a Edición. Hanser Publishers. ISBN 0-19-520720-3, pp. 108, 7-41

21. Szycher M (1999) Capitulo 13. Polyurethane adhesives. Szycher's Handbook of Polyurethane. Florida, EEUU: CRC Press, Boca Raton. ISBN 0-8493-0602-7, pp.1-16

22. Orgilés-Calpena E, Arán-Aís F, Torró-Palau AM, Orgilés-Barceló C (2018) New adhesive technologies in the footwear industry. A. Pizzi and K.L. Mittal. Handbook of adhesive technology. s.l. 3rd Edition: CRC Press, pp 603-618

23. Ruana M, Luana H, Wanga G, Shen M (2019) Bio-polyols synthesized from bio-based 1,3-propanediol and applications on polyurethane reactive hot melt adhesives.Industrial crops and products. pp 436-444

24. Tenorio Alfonso A, Sánchez MC, Franco JM (2019) Synthesis and mechanical properties of bio-sourced polyurethane adhesives obtained from castor oil and MDI-modified cellulose acetate: influence of cellulose acetate modification. Int J Adhes Adhes 95:102404

25. Zhang C, Madbouly SA, Kessler MR (2015) Biobased polyurethanes prepared from different vegetable oils. ACS Appl Mater Interfaces. 2: 1226-1233

26. Ding H, Wang J, Wang C, Chu F (2016) Synthesis of a novel phosphorus and nitrogen-containing bio-based polyols and its application in flam retardant polyurethane sealant. Polym Degrad Stab 124:43-50

27. Fernandez -Dacosta C, Van der Spek M, Hung CR, Oregionni GD, Skagestad R, Parihar P, Gokak DT, Stromman AH, Ramirez A (2017) Prospective techno-economic and enviromental assessment of carbon capture at a refinery and CO2 utilization in polyol synthesis. J CO2 Utili 21:405-422

28. Parcheta P, Glowinska E, Datt J (2020) Effect of bio-based components on the chemical structure, thermal stability and mechanical properties of green thermoplastic polyurethane elastomers. Eur Polym J. 2:109422

29. Sahoo S, Mohanty S, Kumar Nayak S (2018) Biobased polyurethane adhesive over petroleum-based adhesive:use of renewable resource. J Macromol Sci 55:36-48

30. Orgilés Calpena E, Arán Aís F, Torró Palau AM, Orgilés Barceló C (2016) Novel polyurethane reactive hot-melt adhesives based on polycarbonate polyols derived from CO2 for the footwear industry. Int J Adhes Adhes. 5:218-224

31. Datasheet of Hoopol F-580 polyadipate polyol,Synthesia Technology, Spain

32. Datasheet of BIO-HOOPOL Synthesia Technology, Spain

33. Datasheet of polyol cardyon, Covestro, Germany

34. Orgilés Calpena E, Carbonell Blasco P, Pérez Limiñana MA (2019) Sustainable polyurethane adhesives for footwear based on an algal biomass co-product as macroglycol. Porto: s.n., In: 5th international conference on structural adhesive bonding

35. EN 1242. Standard test method for determination of isocyanate content

36. EN 1238. Adhesives-determination of softening point of thermoplastic adhesives (ring and ball)

37. ASTM D3236-15. Test method for apparent viscosity of hot melt adhesives and coating materials 
38. Orgilés-Calpena E, Arán-aís F, Torró-Palau AM, Orgilés-Barceló C (2013) Biodegradable polyurethane adhesives based on polyols derived from renewable resources. Proceeding of the Insitution of Mechanical Engineers Part L: Journal of Materials: Design and Applications. 228; 125-136

39. EN 1392. Adhesives for leather and materials for footwear. Solvent-based and dispersion adhesives. Test methods to measure bond strength under specific conditions

40. Orgilés-Calpena E, Arán-Aís F, Torró-Palau AM, Orgilés-Barceló C (2014) Synthesis and characterisation of potentially biodegradable polyurethane adhesives from soybased polyols. Polym Renew Resour 5:99-113

41. Rocha-Gouveia J, Ramos de Sousa Junior R, Orzari-Ribeiro A, Adrianao-Saraiva S, Jackson dos Santos D (2021) Effect of soft segment molecular weight and $\mathrm{NCO}: \mathrm{OH}$ ratio on thermomechanical properties of lignin-based thermoplastic polyurethane adhesive. Eur Polymer J 131:109690

42. Ghasemlou M, Daver F, Ivanova EP, Adhikari B (2019) Polyurethanes from seed oil-based polyols: A review of synthesis, mechanical and thermal properties. Ind Crops Prod 142:111841

43. EN 15307 (2015) Adhesives for leather and footwear materials. Sole- upper bonds. Minimum strength requirements.

\section{Publisher's Note}

Springer Nature remains neutral with regard to jurisdictional claims in published maps and institutional affiliations.

\section{Submit your manuscript to a SpringerOpen ${ }^{\circ}$} journal and benefit from:

- Convenient online submission

- Rigorous peer review

- Open access: articles freely available online

- High visibility within the field

- Retaining the copyright to your article

Submit your next manuscript at $\boldsymbol{\Delta}$ springeropen.com 